\title{
¿ALGO MÁS QUE MÚSICA? REFLEXIONES TRAS LA POSMODERNIDAD
}

\author{
Antonio Notario Ruiz \\ Universidad de Salamanca
}

RESUMEN: En este ensayo presento algunas reflexiones a partir de un grupo heterogéneo de textos de autores que han pensado las crisis del siglo XX y sus repercusiones para el debate sobre lo que la música sea en este momento de la historia. A la sombra de la posmodernidad, destaco algunos acontecimientos que emergen como posibles claves para pensar las artes sonoras conjuntamente, como la importancia del cuerpo a través de la danza, del gesto y de una nueva vocalidad o la ampliación de los límites del sonido aceptable artísticamente de la mano de John Cage, Pierre Schaeffer o Murray Schafer.

Palabras clave: Creación sonora, escucha, estética, posmodernidad.

\section{ANYTHING MORE THAN MUSIC? REFLECTIONS AFTER POSTMODERNISM}

ABSTRACT: In this essay I present some reflections from a diverse group of texts by authors who have thought about the twentieth century crisis and its implications for the debate about what the music is at this moment in the history. In the shadow of postmodernism I want to highlight some events that emerge as potential keys to think in conjunction the sonic arts, and the importance of the body through dance, gesture and a new vocalism or expanding the boundaries of acceptable sound artistically by John Cage, Pierre Schaeffer or Murray Schafer.

Keywords: Sound creation, listening, aesthetics, postmodernism. 
Thomas Schmitt señaló hace ya algún tiempo', en mi opinión acertadamente, que el siglo XX no ha conseguido el consenso respecto a lo que se entiende como música, a diferencia de lo que sucedió en otras épocas. Al menos esa es la sensación que produce la homogeneidad de discursos y la continuidad de las claves sobre las que se asientan los mismos. Es cierto, sin embargo, que habría que revisar en profundidad la opinión y la reflexión sobre la música de cada una de las épocas, a la luz de los documentos que aparecen en la investigación histórica o de las claves nuevas de lectura que proporciona la crítica. Pero no cabe duda de que la historia de la cultura occidental se ha desarrollado durante siglos en una suerte de monismo, al menos estéti$\mathrm{co}$, que ha consagrado algunos conceptos dentro de lo que Adorno consideraba como 'evidente' y que, sin salir de la órbita de la Teoría Crítica, denomino como Teoría Tradicional ${ }^{2}$. El concepto de Música, como el de Arte-con mayúsculas si se trata de esa larga etapa- no ha requerido de especiales aclaraciones durante siglos, ya que nada había que pudiera perturbar el desarrollo de todo lo referido a esos conceptos. Sí, es cierto que ha habido matices, mutaciones, progresos... pero siempre desde la perspectiva de las metafísicas de la belleza. El monismo estético ha mantenido durante siglos la frontera nítida entre lo aceptable artísticamente y lo no aceptable, se tratara de colores, palabras, sonidos o volúmenes. Solo así es comprensible una Poética como la de Aristóteles e incluso más todavía, la de Horacio que han dictado qué era lo correcto durante siglos. En ese sentido, la complejidad que surge del derrumbe del paradigma monista a finales del siglo XIX ha conllevado la liberación -desgraciadamente, 'emancipación' parece ya un vocablo del pasado- de tendencias creativas que no habrían tenido cabida en los límites anteriores. Y la música no fue ajena a ese proceso, como muestra el propio Schmitt. Pero ahí comienza a surgir un nuevo problema: ¿a quién o a quiénes debemos prestar atención a la hora de investigar el problema del concepto de música durante el siglo XX y en la actualidad? Porque la democratización del nuevo momento que va instaurándose desde comienzos del siglo XX, en el que el monismo de la Teoría Tradicional fue sustituido por la convivencia de paradigmas contrapuestos, es decir, por una situación de pluralismo artístico y estético, ha diversificado también las voces que hablan sobre los problemas. Y, si hasta el siglo XX hay un claro perfil de intelectuales y críticos aureolados de una cierta 'autoridad', a partir de la nueva situación va a diversificarse la opinión. En definitiva, ya no será posible 'un' discurso sino que, acorde con el pluralismo, se producirá una

1. Schmitt, Thomas, "La 'naturaleza' de la música", en García Laborda, José María (2004), La música moderna y contemporánea a través de los escritos de sus protagonistas (una antología de textos comentados). Sevilla, Doble J, pp. 292 ss.

2. Notario, Antonio (2006), "La teoría tradicional de la música", en Piñero Moral, R. (ed.) Octavas falsas. Salamanca, Luso Española, pp. 121-158. 
polifonía de concepciones y opiniones en las que no podrá reclamarse la autoridad para ninguna. De forma que a las tradicionales aproximaciones de filósofos y críticos, e incluso algún compositor, habrá que añadir la de los artistas, los escritores en general, los intérpretes, los medios de comunicación... e incluso de los oyentes anónimos que, siempre que se les concede, harán uso público de su voz. Esta complejidad hace imposible el consenso que emanaba -o parecía emanar- de los textos de otras épocas. Y es una complejidad que ha seguido creciendo al hilo ya no de la pluralidad de las vanguardias históricas sino de la auténtica atomización artística y estética que ha caracterizado el final del siglo XX y parece seguir vigente en el siglo XXI. Ya no es que convivan diferentes y variados paradigmas sino que en muchas ocasiones, un mismo artista en cada una de sus obras -o en grupos reducidos de ellas- articula o utiliza diferentes paradigmas combinados. Una complejidad casi infinitesimal que, además, ha crecido exponencialmente con la posmodernidad y su afán de mezcla y cambalache. Por otra parte, y en la misma estela de los 'logros' posmodernos más que en los de las rupturas de las vanguardias históricas, en la actualidad se ha producido un difuminado casi completo de los límites entre estilos y géneros -o al menos eso pretenden algunos académicos bien protegidos tras sus cargos profundamente jerárquicos- en nombre de una corrección política que instaura unos límites diferentes. Me refiero al hecho de que hablar de música en estos compases iniciales del siglo XXI es hacerlo de cualquier discurso o texto sonoro creado o generado por cualquier ciudadano o ciudadana del mundo, siguiendo códigos aunque sea lejanamente emparentados con las normas clásicas del arte sonoro, con instrumentos reales o virtuales o con la voz humana. El discurso oficial -en mi opinión, ideológicamente- defiende ahora una ausencia completa de jerarquía, aunque sea desde instituciones tan jerarquizadas como la crítica mediática o la Universidad. Aunque volveré a mencionarlo, uno de los 'maestros' en la unión forzada e innecesaria de nombres propios es Alex Ross, pero en la crítica nacional o en textos de autores tan reconocidos como Franco Fabbri se encuentran otros muchos ejemplos. Esta es una situación también nueva en la historia cultural: además de estar firmados por una vagina o un pene -utilizados en una u otra forma es igual-, los compases valen lo mismo provengan de donde provengan y sean realizados desde el autodidactismo más puro o desde los cursos de composición de Darmstadt o de la Fundación Royaumont. De forma que las posibilidades de aproximarse a una definición consensuada u homogénea de la música se complican todavía más. En definitiva si, volviendo al texto citado de Schmitt, ha sido posible en algún momento tomar en consideración los textos de Charles Ives, John Cage o Ernest Ansermet para dialogar con ellos y establecer algunos elementos de cara a la definición de lo que el siglo XX ha entendido por música, ahora se hace necesario ampliar el espectro de referencias para intentar aproximarse a la complejidad que plantea el problema. No agotaré las posibilidades, pero planteo algunas cuestiones que me parecen 
relevantes y dignas de ser tenidas en cuenta. Por una parte, presento algunas reflexiones en diálogo con autores muy diversos y que no siempre pertenecen al ámbito musical. Por otra, planteo dos fenómenos que no han sido tenidos en cuenta suficientemente y que creo que son susceptibles de ser atendidos con el objetivo de alcanzar una comprensión más profunda del problema: la trascendencia de lo que denomino como 'giro sonoro' de las artes y de la música y la importancia de la escucha.

El título que he escogido para este breve ensayo procede de la lectura de un libro de Simon Reynolds, Después del rock. Para el lector obligado a recibir solo la cultura traducida, su autor ha sido conocido recientemente y sobre todo gracias al lanzamiento de su último libro, Retromanía. Reynolds ha realizado desde hace años una tarea de crítica musical, especialmente de las diferentes corrientes anglosajonas que han nacido de los impulsos del rock. Muy crítico no solo con los músicos sino con la propia crítica, sus textos combinan un conocimiento muy serio de los grupos musicales, por efímeros y poco famosos que hayan podido ser, con citas de Nietzsche o de filósofos vinculados a la llamada French Theory, como Derrida o Foucault. Desde esa posición peculiar y tan característica de los últimos años, Reynolds se pregunta: ¿qué es lo que viene después del posmodernismo? La pregunta de Reynolds resonaba en mis oídos cuando recibí la amable invitación a participar en el debate escrito en torno a la pregunta, nada banal, sobre lo que la música sea o siga siendo a estas alturas de la historia. La pregunta y la oportunidad son motivo, en sí, de reflexión. Tal vez por el tipo de ocupaciones y preocupaciones en que me encuentro en este momento, he vinculado la pregunta con la situación de indefinición de la época actual, provocada en buena medida por el efecto, en muchos sentidos devastador, de la época anterior: la posmodernidad. El hecho mismo de preguntarse algo así puede considerarse como un claro síntoma de que la posmodernidad ha finalizado sin remedio. A pesar de que no existe consenso sobre el calificativo que pueda aplicarse a este momento cultural -se oye hablar de post-postmodernidad, de transmodernidad, de segunda modernidad...- sí parece claro que, ni en la realidad política y social, ni en el reducido ámbito cultural, puede seguir considerándose vigente el fenómeno posmoderno. Va siendo hora, entonces, de llevar a cabo tareas de reconocimiento sobre los territorios de las artes y de la estética para ver qué ha quedado tras el paso del vendaval posmoderno por la cultura. A pesar de no contarme entre los enemigos de las múltiples variantes del discurso posmoderno, sí he podido apreciar, como tantos, que en algunas de sus actitudes estaba incurriendo en aquello que se suele mencionar como 'tirar el niño con el agua de la bañera'. El final de los grandes relatos, los apropiacionismos de todo tipo, la despedida de la historia, todos los rasgos principales, en fin, han conllevado la apertura de múltiples posibilidades. Pero también se han desmoronado algunas seguridades epistemológicas o metodológicas que han transformado tanto los ámbitos creativos como el estudio y la investigación académica. Lo explica muy bien Terry Eagleton, él sí poco 
amigo de la posmodernidad, al hablar del "culto posmoderno"3. En sus textos, como en los de Finkielkraut, Steiner e incluso Todorov, se encuentra una Ilamada de alerta frente a los aspectos que podríamos denominar como 'nocivos' de la posmodernidad. Pero, ¿cómo ha afectado todo ese proceso de deconstrucción cultural a la música? No es posible llevar a cabo un análisis completo de todas las variaciones producidas al hilo de la ideología posmoderna, pero sí presento una breve panorámica que recoge algunas visiones críticas que pueden fundamentar un análisis del presente. Algunos autores no han escrito sobre música o lo han hecho tangencialmente -como Steiner en Lenguaje y silencio ${ }^{4}$, pero no es difícil extender a la música lo que plantean de forma general o en relación con otras artes.

No puede dejarse de lado que la posmodernidad entendida como suma de intenciones, prácticas y procesos artísticos, culturales y mediáticos, ha sido posible gracias a la crisis cultural previa, incluso al fracaso de las vanguardias históricas y a la configuración de un orden económico y político heredero de las consecuencias de la Segunda Guerra Mundial. En ese sentido, no puede hablarse solamente de lo que la posmodernidad ha realizado como impulso original, sino que hay que contemplar también la crisis que empieza a emerger en los años treinta del siglo XX. Uno de los primeros en mencionar lo que después ha ido configurándose como una voluntad destructiva de la cultura occidental, fue Aldous Huxley, en una breve pero muy relevante colección de ensayos que lleva como título Music at Night and other Essays (1931). En el titulado El esnobismo de la estupidez y de la ignorancia, Huxley comenta el giro que se ha producido en la valoración de la cultura, que ha pasado de ser un bien deseable a ser motivo de desprestigio:

Quienes permanecen tranquilamente sentados en una habitación, sin más que sus pensamientos por toda compañía y quizás un libro para entretenerse, son representados como individuos miserables, ridículos e incluso inmorales. La felicidad es producto del ruido, de la compañía, del movimiento, de la posesión de objetos. Cuanto más ruido escuche uno, cuantas más personas tenga alrededor, cuanto más deprisa se desplace, cuantos más objetos posea, más feliz será.

Todos ellos hablan desde una conciencia claramente moderna y, por lo tanto, sienten la amenaza de lo que puede conllevar la pérdida de las referencias culturales con un contenido 'espiritual' -en el sentido más amplio del término-. Por las mismas fechas que Huxley, Adorno, Walter Benjamin o incluso Ortega

3. Eagleton, Ferry (2005), Después de la teoría. Trad. Ricardo García Pérez. Barcelona, Debate.

4. Steiner, George (2003), "Moisés y Aarón, de Schönberg", en Lenguaje y silencio. Ensayos sobre la literatura, el lenguaje y lo inhumano. Barcelona, Gedisa, pp. 149-161. 
y Gasset constataban que estaba produciéndose una gran mutación que no tenía que ver solo con los acontecimientos que desembocaron en la tragedia de la Segunda Guerra Mundial. Para ellos, estaba produciéndose una crisis que tenía un alcance mucho mayor. En algunos casos lo formularon como el problema de la técnica, en otros como la dialéctica de la Ilustración o como la crisis del individuo, pero en todos ellos se desconfiaba de lo que pudiera traer un futuro que parecía dispuesto a modificar radicalmente elementos de la cultura que parecían seguros, cuando no a silenciarlos.

En el caso de Adorno, fue cobrando conciencia progresivamente de esa situación no sólo en relación con la música desde la composición y la interpretación, sino a través de sus experiencias de investigación en sociología empírica en el Estudio de Música del Princeton Radio Research Project, publicadas recientemente ${ }^{5}$. Mediante la propuesta de una nueva escucha, de una escucha estructural, Adorno comenzó a defender, antes incluso del exilio, la posibilidad misma de una forma de comportarse ante la música como propuesta utópica, incluso de un nuevo tipo humano o de una sociedad en la que el individuo pudiera comportarse libremente. Su planteamiento consiste, en definitiva, en contrarrestar lo que percibió claramente en los Estados Unidos y que supo ver como antecedente de lo que más tarde se ha denominado como 'globalización'. Aunque Adorno afirmaba haber trabajado más como músico que como sociólogo, años más tarde cobró conciencia de lo que denominó como 'momento sociológico' de este trabajo. De esta forma, a caballo entre las experiencias que dichos estudios le proporcionaron y la cotidianidad extracientífica -como la constatación de 'la desaparición del hombre culto en el sentido europeo'-, Adorno alcanzó una situación intelectual y personal muy alejada de la anterior al exilio. Lo explica él mismo:

En Estados Unidos me liberé de la ingenuidad de la credulidad cultural, adquirí la capacidad de ver desde fuera de la cultura. Me explicaré: a despecho de toda mi crítica social, y pese a que tenía conciencia del predominio de la economía, desde siempre tuve por evidente la absoluta preeminencia del espíritu. Que esa evidencia no es válida sin más vine a saberlo en América, donde no impera ningún respeto tácito por lo espiritual como en el centro y el occidente de Europa... Ello afectaba en especial a los supuestos europeos de cultura musical de que yo estaba embebido ${ }^{6}$.

El contraste espiritual entre los ambientes vieneses y berlineses en los que había convivido con Alban Berg o Hanns Eisler, y la forma de vida artística de ambos lugares con la cultura de masas en estado puro que encontró en los Esta-

5. Adorno, Theodor W. (2010), Currents of Music. Eleménts pour une théorie de la radio. Trad. Pierre Arnoux. Paris, ed. de la Maison des Sciences de I'homme.

6. Adorno, Theodor W. (1973), Consignas. Buenos Aires, Amorrortu. 
dos Unidos, produjo una radicalización en sus planteamientos que queda patente en los escritos de ese momento, sobre todo en el artículo de 1938, El carácter fetichista de la música y la regresión del oído ${ }^{7}$, utilizado posteriormente en la mucho menos radical Filosofía de la nueva música, de 1949. Precisamente en ese ensayo de 1938 sobre la regresión del escuchar, aparece claramente la crítica de la industria cultural ligada a la perspectiva de un humanismo musical que ganará terreno progresivamente en la obra de Adorno.

El ensayo "Sobre el carácter fetichista en la música y la regresión del escuchar" fue la primera decantación de las experiencias americanas del autor, cuando dirigió la Sección musical del Princeton Radio Research Project. [...] Los hechos objetivos sociológico-musicales con los que se encontró el autor a la sazón, diéronle por vez primera una serie de ideas acerca de modificaciones antropológicas que superan con mucho las fronteras del campo concreto estricto y delimitado. [...] Al mismo tiempo, el ensayo acerca del "carácter fetichista" de la música quiso ser en su día una réplica al trabajo de Walter Benjamin, Das Kunstwerk im Zeitalter seiner technischen Reproduzierbarkeit, que figura en el tomo primero de sus obras completas ${ }^{8}$.

Por otra parte, Adorno empieza a cobrar conciencia del impacto social de los nuevos medios de comunicación -concretamente el cine y la radio- que colaboran en el proceso de mercantilización. A lo largo de toda la década ha ido aumentando la preocupación por el impacto de estos nuevos medios, como se puede comprobar en los ensayos de Béla Bartók, Walter Benjamin y José Ortega y Gasset, en señalar los 'peligros' que entrañaba su utilización sin control. Adorno volverá más detenidamente a ellos en la etapa del exilio estadounidense9 .

En su reflexión sobre el impacto de la técnica, Adorno descubre una doble vertiente. Por una parte, la difusión a través de la radio y de la venta de discos, que crea una situación nueva por lo que se refiere a los hábitos de audición y, al mismo tiempo, desplaza los viejos cauces de acercamiento a la música a través de la ejecución doméstica, una de cuyas formas era la lectura a cuatro manos de reducciones para piano de obras orquestales ${ }^{10}$. Las posibilidades de democratización de la música pagan inmediatamente el precio de la calidad y,

7. Adorno, Theodor W. (1966), "Sobre el carácter fetichista y la regresión del oído", en Disonancias. Madrid, Rialp.

8. Adorno, Theodor W. (1966), Disonancias. Madrid, Rialp, pp. 12-13. Prefacio de 1956.

9. Bartók, Béla (1979), "Música mecanizada", en Escritos sobre música popular. Traducción de Roberto V. Raschella. México, Siglo XXI, pp. 222-235. Ortega y Gasset, José (2013), La rebelión de las masas. Edición de Domingo Hernández Sánchez. Madrid, Técnos. Benjamin, Walter (1992), La obra de arte en la era de la reproductibilidad técnica. Madrid, Taurus, pp. 15-57.

10. Cfr. Adorno, Theodor W. (1985), "A cuatro manos, una vez más", en Impromptus. Barcelona, Laia. 
sobre todo, el de las posibilidades del dirigismo cultural a través del control económico de las ondas. La escucha pasiva y atomizada es el objetivo:

...escuchan de un modo atomizado, y disocian lo oído, pero en la disociación desarrollan precisamente ciertas capacidades que resultan harto más difíciles de captar con los conceptos estético-tradicionales que con los del fútbol o la conducción de automóviles ${ }^{11}$.

Y a ese modelo de escucha conviene un tipo de música que va a configurarse como un subproducto de corte neorromántico, limitado en posibilidades artísticas y con todas las características de un producto comercial. Se trata de una música en la que el concepto melódico se ha esclerotizado en una 'melodía en el registro medio-agudo con simetría de ocho compases ${ }^{12}$, al mismo tiempo que las gamas dinámicas se han simplificado de manera que no existan tensiones ${ }^{13}$. Por otra parte, Adorno señala la aparición, con mucha presencia social, de la figura del arreglista, mucho más importante que la del propio compositor. El arreglista facilita la interpretación reduciendo la plantilla instrumental -es decir, abaratando los costes de las orquestas- y maquillando los colores orquestales al pretendido gusto del público ${ }^{14}$.

La música, que se había librado hasta la fecha de pertenecer al 'mobiliario burgués' en virtud de su inaprensibilidad, pasa a formar parte del paisaje del hombre masa, que discute sobre intérpretes como lo hace sobre deportistas o sobre estrellas de cine, y que, además, puede coleccionar las grabaciones de sus ídolos e incluso convertirse en un 'entendido'. Porque el fetichismo da lugar al surgimiento de nuevos valores vinculados a la voz, a la dirección de orquesta y a la interpretación virtuosística. Y Adorno no deja de señalar de qué manera esos valores son un paso en la dirección de la comicidad con la que se desprestigia a la música ${ }^{15}$. Pero también señala, ya en la dirección de Dialéctica de la Ilustración, cómo los mismos elementos que en algún momento condujeron a la proscripción de la música son ahora los que forman parte de los nuevos fenómenos. Se establece un estereotipo que homogeneiza los productos musicales mercantiles: la música ligera y la música clásica. La nueva mercancía, de la que queda excluido el goce, bajo la apariencia de juego, sólo es susceptible de la identificación con el fetiche ${ }^{16}$.

11. Adorno, Theodor W. (1966), "Sobre el carácter fetichista y la regresión del oído", en Disonancias. Madrid, Rialp, 1966, p. 46.

12. Ib. p. 28.

13. Ib. p. 42.

14. Ib. pp 38-41.

15. lb. p. 67.

16. Ib. p. 49. 
Pero más allá de las claves que ofrece Adorno, no muy bien aceptado en los últimos años por la acusación de elitismo, mandarinismo cultural, etc., es preciso continuar revisando diferentes lecturas sobre la situación actual de la música. Sin salir del ámbito de las obras publicadas en España o traducidas en los últimos años al castellano, es difícil establecer un criterio que permita determinar, más allá de los clásicos citados, a qué o a quién habría que prestar más atención. En el discurso filosófico ha brillado con luz propia la obra del recientemente fallecido Eugenio Trías (1942-2013). Ha sido el primero de los filósofos españoles con un claro perfil público y una presencia mediática habitual en prestar atención a la música. Comenzó en los lejanos setenta dando cuenta crítica de algunos textos de Charles Rosen sobre Haydn -Drama e identidad (1974) - y más tarde ha dedicado a la música multitud de conferencias y dos monografías en las que ha repasado pormenorizadamente muchas obras de la Ilamada tradición culta o seria ${ }^{17}$. Su discurso, muy profundo en cuanto a lo estrictamente filosófico -la denominada filosofía del límite-, sin embargo, en cuestiones musicales iba poco más allá de Platón. En sí mismo este es un rasgo también posmoderno: puestos a elegir, el autor se queda en un terreno seguro aunque problemático, un terreno que le permite construir un discurso de filosofía de la música que puede mirar de frente incluso a una parte de las obras del siglo XX.

En el ámbito musicológico habría que prestar atención a tendencias tan contrapuestas como la de Nicholas Cook y la de Dahlhaus. Del primero solo se ha traducido hasta la fecha su texto introductorio a la música, completamente posmoderno en su concepción y en sus conclusiones, con la defensa de los elementos 'de género' y multiculturales. Incluso la pésima elección del título por parte del traductor o de los editores muestra una de las peores características posmodernas: la presencia de Madonna y el canto gregoriano juntos, es decir, la mezcla más aparentemente desenfadada, iconoclasta, radical, provocativa... pero solo para intentar vender un poco más. Si se piensa que el autor es profesor universitario en un sistema tan jerárquico como el británico, se comprende que sus intenciones son más académicas y científicas que las del editor o el traductor. Pero el título de la edición española vale como ejemplo de lo que se ha entendido como posmoderno. Es cierto que en aquellos años locos se realizaron algunos 'mix' entre melodías gregorianas y diferentes estilos de músicas de discoteca. Pero no ha quedado gran cosa de aquellas producciones y no está claro que no hayan sido más que ejercicios de marketing, elaboración de mercancías con fecha de caducidad sin sustrato teórico alguno. Dahlhaus, sin embargo es moderno por completo, pero su reivindicación de la historia, o de la revisión de la historia, si se prefiere, no está lejos de la revisión del histori-

17. Trías, Eugenio (2007), El canto de las sirenas. Barcelona, Galaxia. (2010), La imaginación sonora. Barcelona, Galaxia. 
cismo que ha acometido la posmodernidad, e incluso convierte a nuestra época misma en susceptible de una aproximación desapasionada.

Más allá de esos textos -entre otros muchos posibles-, no puede prescindirse de una producción que no nace en el ámbito académico sino en las columnas de prensa general o especializada, o en las reflexiones de aficionados y profesionales de la música que aportan multitud de elementos insoslayables. Me refiero a personajes emergentes en la cultura mediática -al menos en cuanto a las ventas se refiere- como las de Alex Ross y el ya citado Simon Reynolds. Alex Ross escribe en el medio más prestigioso y más consultado por una parte de la intelectualidad bien pensante actual, The New Yorker Review of Books. Sus columnas, como las de sus colegas literarios, sientan, si no doctrina, sí criterio para el consumidor. El éxito de su primer libro traducido al castellano solo se explica desde la necesidad de una guía suficientemente segura a la par que nimbada por ese viejo criterio de autoridad del que parece imposible desprenderse. La posmodernidad penetra en el libro de la mano de la ausencia de respeto a la historia, de la ficcionalización exagerada y de la pretensión de establecer un mismo rasero para obras que son muy diferentes en su valor estético. Pero se hacía necesario un compromiso más explícito con la deconstrucción cultural: el nuevo mainstream, la corrección política presente, exige que se escriban juntos los nombres de personajes completamente independientes para que cualquier Parnaso sea imposible. De ahí el siguiente libro, Escucha esto (2012), en el que se da un paso más, el paso implícito ya en el anterior, pero que consagra la vocación de nivelación cultural: en lugar de encontrar razones musicales para realizar esa reunión artificial de, entre otros, Brahms y los Beatles, ahora de lo que se trata es de que en todos los casos son seres humanos. Esta vocación de mezcla se ha dirigido, bien hacia la música popular urbana, bien hacia las diferentes manifestaciones étnicas. Sin embargo, se mantiene una resistencia muy fuerte frente a la creación más novedosa, frente a los restos de vanguardismo musical. Por eso abordo ahora un aspecto que me ha ocupado en otras ocasiones y que vuelvo a considerar y presentar ahora.

De hecho, sin pretensión de convertir este ensayo en una acumulación de elementos autobiográficos, en la docencia me he encontrado en multitud de ocasiones con la pregunta por la definición de lo que estaba escuchándose en el desarrollo de la clase. "¿Esto es música?" es una pregunta que ha surgido en grupos de alumnos muy diversos entre sí para el célebre 4'33" cageano, la Sequenza III de Berio, para algunas obras de Salvatore Sciarrino y Helmut Lachenmann y para la totalidad de las propuestas concretistas, por citar solamente cuatro casos. No es posible pasar por alto que las actitudes posmodernas han aportado elementos positivos al enfoque académico general y a todos los estudios sobre música en particular. El caso de la apertura a una consideración global que destierre el eurocentrismo, los mal Ilamados estudios de género y una mirada respetuosa y atenta hacia las manifestaciones populares son los rasgos que definen ese posmodernismo de progreso. Pero incluso contando con esas aportaciones, 
no solo sigue en pie la pregunta por la definición de la música sino que se plantea incluso la posibilidad de la continuidad de la misma.

Volviendo a Adorno, pueden encontrarse algunas reflexiones que anticipaban ese problema ya en los años sesenta. Es sabido que una de las frases filosóficas que han alcanzado notoriedad más allá de los círculos profesionales, convirtiéndose en tópico de artículos, conferencias y reseñas periodísticas, es la que abre el libro que los editores de Adorno editaron y publicaron como Teoría Estética. Tal y como sucede con otras frases famosas, se pierde una buena parte de su significado al ser apartada del resto de la argumentación que le acompaña, pero tiene un efecto de fetiche $y$, sin duda, como todas las citas, aporta una cierta sensación de seguridad -e incluso de superioridad-a quién la incluye en su discurso. Me refiero, claro, al dictum adorniano que afirma que ha llegado a ser evidente que nada relativo al arte es evidente. No me voy a detener en los problemas que encierra la traducción, pero sí la voy a transcribir completa, es decir, acompañada de las frases que la prolongan y explican, para que recobre una parte de su pertinencia.

Ha llegado a ser evidente que nada referente al arte es evidente: ni en él mismo, ni en su relación con la totalidad, ni siquiera en su derecho a la existencia. [...] El arte podría tener su contenido en su propia transitoriedad. Puede imaginarse y no se trata de ninguna posibilidad abstracta, que la gran música, como algo tardío, sólo fuese posible en un determinado período de la humanidad ${ }^{18}$.

De la misma forma que pueden escucharse voces contra el carácter artístico de muchas de las obras y propuestas contemporáneas que cuelgan en museos y salas de exposiciones, ha ido surgiendo la duda, cuando no la denuncia, del carácter artístico de muchos de los discursos que se escuchan en algunos escenarios. La secuencia de un numeroso público abandonando la sala cuando empieza a sonar cualquier obra contemporánea, incluso las Variaciones op. 27 de Anton Webern, no pertenece a película alguna, sino que es habitual y prueba de esa ruptura del público con determinados discursos que siguen ofreciéndose como musicales. De la misma forma, la pregunta que surge entre alumnos cuando se escuchan determinados fragmentos en clase nos aboca a la misma reflexión. Pero todavía quedaría un ejemplo más claro: la programación de los ciclos de conciertos y de ópera dependientes tanto de entidades públicas como privadas. Salvo aquellas obras que se salvan gracias a una 'guetización', en ciclos específicos que, por otra parte, cada vez sobreviven peor, el público en general tiene acceso solo al denominado 'repertorio', que actúa como un dique perfecto contra la novedad y la renovación de la escucha.

18. Adorno, pp. 11-13 de la edición española. 
Esta situación no es nueva en gran medida. Si se recuerda el inicio de Musicalia, el único artículo que Ortega y Gasset dedica a la música, puede comprobarse como el filósofo madrileño constata la dificultad que el arte nuevo plantea siempre al público y la necesidad de un tiempo de adaptación, una especie de adecuación lenta a la nueva sensibilidad representada por las obras nuevas. Si él habla en ese artículo de las dificultades que siente el público ante las obras de Debussy frente a la aceptación ya permanente del repertorio clásico y romántico, centrado siempre en Beethoven, cabe preguntarse si se podría establecer ahora qué dialéctica se da entre lo nuevo y lo ya conocido en la creación musical. ¿Hay algún compositor o compositora que pueda representar ese papel de música nueva, emergente y llamada a ser incorporada a la escucha habitual? ¿Hay algo, incluso en las músicas que Adorno denominaba como de entretenimiento, que sea 'nuevo' más allá de la combinación de elementos tecnológicos gracias al sampleado de uno u otro sonido? No parece que sea así: desde hace años hay obras que permanecen desconocidas para los aficionados e incluso para algunos profesionales. Se ha producido una escisión entre la creación y la recepción que indica un cambio de ciclo cultural. El paradigma tradicional de la relación entre los compositores y los públicos, e incluso los profesionales, se ha modificado por completo. La aparición de nuevas formas, especialmente a través de la red, amplía las posibilidades de distribución, pero no parece que afecte a los contenidos. La novedad, como ha señalado acertadamente Domingo Hernández Sánchez, se ha tornado problemática al hilo de la ausencia de futuro, es decir, de fe en el futuro ${ }^{19}$. La música, especialmente, parece no poderse desprender de los momentos más arriesgados del pasado reciente y permanece atada a esos límites sin avanzar un milímetro. Es indiferente que desde el ámbito académico se haya abierto la puerta a una consideración omniabarcante: ahora que todo es relevante, nada es ya relevante.

Pero se habla de música indistintamente para referirse a todo: a lo que el público consume con comodidad, a lo que permanece en circuitos muy reducidos y, por supuesto, a todas las manifestaciones populares, multiculturales, etc. Adorno lo señala con mucha serenidad: al igual que otras formas de cultura como la filosofía, nada permite asegurar que la música, tal como la hemos conocido, sobreviva a las transformaciones sociales. Pero esa posibilidad, que no se debe juzgar precipitadamente como pesimista, lo único que indica es la necesaria apertura a la complejidad de lo presente y la necesidad de contemplar los fenómenos en sí mismos, sin esquemas previos que dificulten su comprensión. En mi opinión, hay dos reflexiones especialmente relevantes de cara al futuro que pueden alimentar todavía el estudio y la investigación, así como las diversas perspectivas educativas. Me refiero a la ampliación de los ámbitos

19. http://www.revistametronomo.com/2012/12/26/el-recuerdo-de-lo-nuevo/ [Fecha de consulta: 30.03.2013] 
artísticos, tanto musicales como no musicales hacia el mundo completo del sonido y, al mismo tiempo, la importancia creciente de propuestas teóricas en torno a la necesidad de una nueva escucha. Ambos están estrechamente relacionados. Al primero lo denomino, como ya he indicado, 'giro sonoro', en buena medida porque se ha hablado en la filosofía de los últimos años de un giro lingüístico, de un giro hermenéutico y se ha prestado muy poca atención a ese proceso que ha puesto de relieve un nuevo ámbito de creación y de experiencia estética.

Entiendo por giro sonoro la apertura de todas las artes, incluida la música, a una nueva actitud ante el sonido que aumenta las posibilidades de creación y de recepción. Ese proceso de apertura se ha producido escalonadamente. La primera etapa del giro sonoro de las artes y de la música se produjo, en mi opinión, en el movimiento interno del propio lenguaje musical. La lógica del tonalismo llevó a los códigos del encadenamiento armónico y, como consecuencia, de la construcción de melodías, a la crisis de su final. Esta se manifestó ya en las composiciones del último tercio del siglo XIX, pero cristalizó en varias direcciones una vez comenzado el siglo XX. Todos los códigos nuevos, más o menos alejados del tonalismo, facilitaron el acercamiento a una nueva escucha y a una nueva actitud frente al sonido. En cada uno de esos códigos se aportaron elementos para el desencadenamiento de varios procesos que coinciden en la dirección de abrir la música a una nueva etapa. Pero, a diferencia de otros momentos históricos que ya presenciaron la dialéctica entre prácticas antiguas y modernas, en esos años iniciales del siglo XX, la novedad tuvo un carácter radical.

En mi opinión, ese giro es comparable a otros dos hitos: la reincorporación de la polifonía a la música occidental, que implica para el arte de los sonidos tanto como la perspectiva para la pintura; la creación del género dramático a finales del siglo XVI, el dramma in musica, que va a establecer una relación nueva entre la palabra y el arte de los sonidos, pero a la vez va a ampliar el campo abierto para el desarrollo de la música instrumental. Este tercer momento es el de la apertura de la música al completo ámbito del sonido que tradicionalmente había quedado extramuros de su férreo sistema de organización. Condujo de la notación a las grafías; de los instrumentos a los generadores sonoros; de las contraposiciones convencionales entre matices como forte y piano a una ampliación dinámica; también a una ampliación agógica; a una ampliación rítmica; a nuevas gramáticas; a nuevas poéticas; a un nuevo concepto de tiempo; de las formas musicales a las estructuras; a un nuevo concepto de silencio; e, inevitablemente, a una nueva escucha. En todas esas transformaciones jugaron un papel muy importante dos elementos claramente corporales: la danza y la vocalidad. Y ahí se amplía la confluencia entre la evolución de la música en las vanguardias históricas y la del resto de las artes: el nuevo papel del cuerpo. 
Desde las vanguardias históricas, el papel del cuerpo ha ido adquiriendo una centralidad nueva ${ }^{20}$. Esta tendencia se ha acentuado a partir de la Segunda Guerra Mundial. Desde el movimiento Die Brücke y su gusto un tanto naif por el cuerpo hasta los accionismos de todo tipo, desde la fotografía naturalista hasta el body art, y, por supuesto, la eclosión de las tendencias de género, se puede hablar de una gran diversidad de estéticas del cuerpo. Liberado de los tabúes de la moral judeocristiana predominante durante siglos, el cuerpo es contemplado de una forma nueva. En el caso de la música, sin embargo, el cuerpo ha sido siempre fundamental y ha desempeñado un papel protagonista. Dos de los ámbitos de ese protagonismo son el canto, pura conjugación muscular del diafragma y la columna de aire que impulsa con las cuerdas vocales, y la danza, música hecha cuerpo o viceversa. Sin embargo, la estética musical no ha prestado habitualmente una atención específica a este binomio. Salvo algunas alusiones en la estética hegeliana, hay que recurrir a los narradores y los poetas para encontrar menciones a la influencia del canto y, en el caso de la danza, hay que esperar hasta Valèry para que la incorpore a sus discursos, mitad estéticos mitad literarios.

El canto ha sido la columna de la música occidental y, en esa misma medi$\mathrm{da}$, ha resultado beneficiario de comentarios desde antiguo ${ }^{21}$. El poder del canto para seducir y conducir a un estado emocional de enajenación, como en el caso del canto de las sirenas, sirve como pórtico para evaluar el papel que ha desempeñado en la literatura occidental y que se corresponde con su protagonismo en la propia música. En coherencia con esa importancia histórica, desde el comienzo del giro sonoro, la voz y el canto han desempeñado un papel central. Dos son los posibles elementos para analizar ese hecho. Por una parte, en cuanto que relacionada básicamente con la palabra, no era pensable que se produjeran cambios en los textos y que estos no repercutieran en el instrumento emisor, la voz. Desde Baudelaire y más todavía desde el simbolismo, la poesía había ido abandonando las formas antiguas y avanzando en busca de nuevas posibilidades de expresión. Los compositores recibieron inmediatamente ese cambio y lo asumieron plenamente. Para la composición musical, la morfología había dependido durante siglos de las formas poéticas y desde finales del siglo XIX se abría la

20. Cfr. Danto, A.C. (2003), El cuerpo / El problema del cuerpo. Trad. F. Abad. Madrid, Síntesis; Ramírez, J.A. (2003), Corpus solus. Para un mapa del cuerpo en el arte contemporáneo. Madrid, Siruela; Rella, F. (1999), En los confines del cuerpo. Buenos Aires, Nueva Visión. Romero de Solís, D., Díaz-Urmeneta, J.B., y López Lloret, J. (1999), Variaciones sobre el cuerpo. SeviIla, Servicio de Publicaciones de la Universidad de Sevilla.

21. Cfr. Bañó, F. (2003), La antitécnica. La impostación vocal en la ópera, teatro musical, jazz, música ligera y agrupaciones corales. Madrid, Alpuerto; Cornut, G. (1988), La voz. México, Fondo de Cultura Económico; Dunn, L., Jones, N. (1994), Embodied voices representing female vocality in western culture. Cambridge, University Press; Ferrer Serra, J. (2001), Teoría y práctica del canto. Barcelona, Herder. 
puerta a nuevas organizaciones poéticas, lo que quería decir, también, a nuevas formas musicales. Baudelaire, Mallarmé, Verlaine... todos los poetas de la transición a una nueva forma de expresión fueron musicados inmediatamente. Pero, en segundo lugar, las nuevas necesidades de la expresión poética conllevaban nuevas necesidades de expresión musical. La forma de cantar sonetos clásicos o románticos no podía mantenerse inalterada si de lo que se trataba era de cantar en versos libres o en formas más flexibles. Y en este aspecto, forma y contenido no son, tampoco, separables. Si se piensa en Pierrot lunaire y en la nueva vocalidad que Schönberg utiliza para ese texto, habría que preguntarse por una hipotético recurso al canto lírico clásico. Y la interpretación, a pesar de que pudiera lucir mejor para algunos públicos, no haría justicia al texto en la misma medida que lo hace el Sprechgesang recién 'inventado'.

Hay, sin embargo, un elemento que no dependía de la poesía, o no estrictamente, en el desarrollo de las nuevas formas de vocalidad y sí mucho de los nuevos imperativos estéticos de las vanguardias históricas. Me refiero a la investigación tímbrica. Aunque es menos habitual prestar atención a ese aspecto, ya que la Teoría Tradicional prestigia exageradamente la melodía por encima de cualquier otro elemento musical, la sensibilidad para el color de los sonidos desempeñó un papel central en los cambios desde el interior de la música. Sin abandonar a los compositores vieneses y a pesar de la desconfianza de Stravinsky hacia el procedimiento ${ }^{22}$, la melodía de timbres -Klangfarbemelodie- era extensible a la voz. Si se investigaban las nuevas posibilidades tímbricas de los instrumentos musicales, la voz no podía quedar al margen. Esto no implicaba renunciar a la utilización convencional de los instrumentos ni tampoco de la voz, pero sí una exploración sistemática de lo que era posible. Precisamente Stravinsky tomó buena nota y en 1913 compuso las Tres piezas de la Lírica Japonesa en las que, sin recurrir al sprechgesang sí que exige de la intérprete un esfuerzo para explotar las posibilidades vocales al máximo.

El camino iniciado en las vanguardias pasaba también por la ópera. Aprovechando el resultado de esa especie de laboratorio de pruebas que es la música de cámara, Alban Berg llevó hasta la ópera una nueva forma de pensar el canto. Aunque Wozzeck y Lulú se representen en los teatros líricos, pertenecen a un tipo de repertorio específico, de gran dificultad técnica para los cantantes que, de hecho, han de especializarse en las formas de emisión que se les solicitan. Aparte de que los roles son más activos y requieren una formación actoral más intensa que para cantar las óperas históricas, la voz ha de realizar un esfuerzo difícilmente compatible con el mantenimiento de un repertorio más clásico. Pero el gran cambio se iba a producir después de la Segunda Guerra

22. Craft, Robert (1991), Conversaciones con Igor Stravinsky. Trad. José María Martín Triana. Madrid, Alianza Música, p. 157. 
Mundial aunque venía preparado por los desarrollos ya mencionados y por la asunción de las nuevas posibilidades de otras prácticas artística. John Cage, con su Aria (1958), estableció un verdadero catálogo de las posibilidades de utilización de la voz. Incluso desde el punto de vista gráfico no quedaban ya puntos de conexión con las anotaciones de la música convencional: el eje de alturas se había difuminado de forma que quedaba al arbitrio del intérprete establecer cuáles iban a ser las frecuencias a utilizar. Lo mismo sucedía con los ritmos y tempos. Un nuevo código gráfico permitía a la intérprete reconocer el gesto sonoro asociado con los colores. Además del canto lírico, todo tipo de falsetes, jadeos, murmullos, susurros, también voz hablada y, por supuesto, imitaciones de acentos diversos. Pocos años después, en 1966, fue Luciano Berio, con la Tercera Secuencia, el que, con mayor concisión, añadió todavía algunas posibilidades a las nuevas formas de utilización de la voz. Dos años más tarde esas novedades fueron incorporadas al canto coral en una de las obras que mejor representan tanto la energía creativa de las neovanguardias como el estilo peculiar de su autor: la Sinfonía del propio Berio.

A partir de ese momento ya estaba en marcha la pugna entre las tímbricas naturales y las nuevas tecnologías. En un primer momento, los compositores que optaron por la composición electroacústica dieron la espalda por completo a los instrumentos convencionales. Los creyentes en la 'nueva fe' tecnológica, la adecuada al cyberanthropo, como lo denominó Henri Lefebvre, creyeron posible una etapa radicalmente nueva, sin restos del pasado. La síntesis de sonido ocuparía el lugar central durante algunos años. Contempladas desde esa óptica, las obras de Berio y Cage se alzaron como verdaderos manifiestos a favor de las posibilidades sonoras naturales. En cualquier caso, las nuevas tecnologías iban a prestar nuevos recursos a la voz. Especialmente, desde el momento en que los compositores más apegados a la electroacústica comprobaron la posibilidad de llevar a cabo una combinación de procedimientos convencionales y nuevos. Quedó entonces garantizada la posibilidad de un uso mixto de la voz. Los desarrollos de la microfonía, por una parte y, más adelante, de los diversos niveles de software de edición y procesamiento de sonido, terminaban, así, de multiplicar exponencialmente las posibilidades vocales.

Ese nuevo mundo vocal ha sido explorado magistralmente por Kaia Saariaho, la compositora finlandesa que, investigando y trabajando en el IRCAM parisino, ha alumbrado obras en las que la mixtura de voces, amplificadas o no, e instrumentos analógicos e informáticos, se convierten en referente para el futuro. Al menos desde Nuits, adieux, de 1991, para cuarteto vocal y electrónica, no ha dejado de explorar estas posibilidades. Un paso más allá, en su caso, ha sido, inevitablemente, el sumar la imagen a ese tipo de discursos intermediales. Pero, al mismo tiempo que se han producido estos desarrollos en la dirección de las nuevas tecnologías, otros artistas y compositores han preferido profundizar en la dirección que no es accesible para ese mundo tecnológico. 
Uno de ellos ha sido el compositor alemán Helmut Lachenmann (1935), al que algunas veces se califica como creador de música concreta instrumental ya que en sus obras, especialmente en las más recientes, investiga el ámbito de los metasonidos asociados con la emisión de los sonidos convencionales de los instrumentos y, a la vez, todas las posibilidades de utilización no convencional de los instrumentos convencionales para generar sonido. La voz, una vez más, no podía quedar al margen de este movimiento. Es especialmente en su ópera Das Mädchen mit den Schwefelhölzern (1990-96) donde intenta penetrar en las sonoridades del monólogo interior de la cerillera que sufre la congelación ignorada y olvidada por todos. Como corresponde tanto al estilo de Lachenmann como al complejo texto de la ópera -aunque una parte de la crítica prefiere no considerarla como tal-, que une fragmentos de Leonardo, del cuento de Andersen y de Gudrun Ensslin, una buena parte de la declamación de las dos sopranos en que se desdobla la protagonista se mueven en los límites de lo audible, en la pura frontera del silencio.

Muy diferente es la intención sonora de otro compositor actual que no recurre a las nuevas tecnologías. Me refiero a Salvatore Sciarrino (1947) y su ópera Luci miei traditrici del año 1998. En este caso, el compositor se plantea un diálogo con dos obras del siglo XVII, de Cicognini y Le Jeune, en concreto, que le permiten explorar las formas clásicas de emisión y elaborar una micro-retórica, una condensación de gestos expresivos reducidos a sus elementos constitutivos mínimos. La contracción motívica no rehúye tampoco, al igual que sucede con Lachenmann, la exploración de los límites sonoros que, como hace ese mismo año en Infinito nero, se traducen en la gradación de intensidades casi inaudibles tanto en los instrumentos como en la voz. En ese caso la voz es, en muchas ocasiones, puro gesto de emisión vocal sin resultado sonoro alguno.

Todavía queda una clara y convincente disidencia a las posibilidades de las nuevas tecnologías. Sin renunciar a ellas, claro es, desde el punto de vista del registro o de la amplificación y demás utilidades escénicas, Fátima Miranda viene desarrollando su carrera artística como cantante global. Y por tal entiendo no a quien se especializa en un tipo de canto, casi siempre exclusivo y por lo tanto, lamentablemente cerrado a influencias e intercambios, sino a quien, como hace ella, asume todas las técnicas posibles de canto para, desde el dominio de las mismas, realizar los intercambios menos imaginables o la utilización de cada registro en cada momento adecuado a la expresión. Su investigación le ha llevado no solo a conocer a la perfección las técnicas del canto lírico sino el canto japonés, el del norte de la India y todos aquellos recursos de canto que se encuentran en las culturas populares. Desde un planteamiento siempre irónico en lo conceptual, en trabajos como las Voces de la Voz (1991), Concierto en Canto (1995), ArteSonado (2000) y perVersiones (2011) ha ido pasando de la constatación del atractivo de las diferentes posibilidades de emisión y de los estilos contrapuestos, hasta un intento de síntesis, todavía más complicada des- 
de el punto de vista técnico, y que busca la descontextualización de los repertorios establecidos y que finalmente acaban por encorsetar a la propia música.

Por lo que se refiere a la danza ${ }^{23}$, otro de los pilares de la corporeidad sonora y del giro que comento, hay que señalar que se piensa la mayor parte de las veces desde una cierta ambigüedad. En muchas ocasiones se la considera autónomamente, mientras que en otras se extiende el discurso musical y se le aplica sin solución de continuidad. Desde mi punto de vista, la danza merece un tratamiento autónomo en la estética que, como ya he indicado, no creo que haya recibido todavía. Sí se ha desarrollado en los últimos años la investigación sobre la historia de la danza con el fin de rescatar danzas tradicionales o coreografías históricas que habían quedado arrumbadas por el tiempo. La importancia creciente de ese tipo de estudios sobre la danza en épocas pasadas va terminando con una laguna histórica importante. Así, cada vez tenemos más información sobre las danzas renacentistas y barrocas, incluso en sus pasos, no sólo en las partituras o en las denominaciones. Este es un elemento muy importante de cara a completar nuestra visión de esas épocas, especialmente teniendo en cuenta el impulso humanista, por una parte y la vertiente escénica de la música, por otra. Pero la contemporaneidad sigue lejos del ámbito de la estética, de la filosofía y de la reflexión en general. De cara al giro sonoro, sin embargo, el soporte corporal a través de la danza ha sido básico. Y se hace obligatorio en este caso, citar a Igor Stravinsky y sus tres obras monumentales que en las vanguardias históricas consiguieron, gracias a la presencia visual especialmente $-y$ este rasgo se suele subrayar poco- el favor de los públicos. No cabe duda de que El pájaro de fuego, Petrushka y La consagración de la primavera abrieron una época para la música contemporánea, para la danza y, sin duda, para la cultura occidental. Solo es preciso acudir a la prensa de la época para comprobar el impacto que sobre el público causaron las obras de Stravinsky. Pero ese éxito habría sido impensable sin una coreografía y un ballet que estuviera a la altura de la propuesta. Ese fue el caso de los Ballets Rusos ${ }^{24}$ que, en función de su labor a favor de la danza, constituyen un hito en su historia.

23. Adair, C. (1992), Women and Dance: Sylphs and Sirens. New York, New York University Press; Ashengreen, E. (1986), Jean Cocteau and the Dance. Copenhague, Gyldendal; Banes, S. (1977), Terpsichore in Sneakers: Post-Modern Dance. Midletown, Wesleyan University Press; Brandstetter, G. (2000), Aufforderung zum Tanz: Geschichte und Gedichte. Wien, Reclam; Bremser, M. (1999), Fifty contemporary choreographers. London, New York, Routledge; Colomé, Delfín (2007), Pensar la danza. Madrid, Turner; Cunningham M.; Lesschaeve, J. (1986), Der Tänzer und der Tanz. Gespräche Merce Cunningham mit Jacqueline Lesschaeve. Frankfurt am Main, Fricke; Postuwka, G. (1999), Moderner Tanz und Tanzerziehung: Analyse historischer und gegenwärtiger Entwicklungstendenzen. Schorndorf, Hofmann; Schulze, J. (1999), Dancing Bodies-dancing Gender: Tanz im 20. Jahrhundert aus der Perspektive der Gender-Theorie. Dortmund, Ebersbach; Wiesenthal, G. (1985), Die Schönheit der Sprache des Körpers im Tanz. Salzburg, Residenz.

24. Garafola, L. (1989), Diaghilev's Ballets Russes. New York y Oxford, Oxford University Press. 
Pero más allá del hecho de la confluencia histórica entre las nuevas energías musicales encerradas en la composición de Stravinsky y las que aportaban Nijinsky y los Ballets Rusos, el tercer elemento era el de la adecuación del nuevo movimiento corporal con la nueva sociedad y la nueva sensibilidad naciente. La conversión súbita de un público que en el estreno rechazó La consagración, pero en poco tiempo la convirtió en una obra aclamada, radica en el hecho de que es la obra musical que rompe con una manera de estar corporal, físicamente y no solo para los bailarines, sino para el resto de los espectadores, para cualquier persona de la segunda década del siglo XX. El ritmo y el movimiento de música y danza colaboran en la nueva sociabilidad del cuerpo. Una corporalidad, la decimonónica, que iba a fenecer definitivamente muy poco después en las trincheras de la Primera Guerra Mundial. Pero antes del final bélico, la danza contemporánea había conquistado uno de sus méritos no menores. Porque si se puede afirmar que la música desempeña una tarea de sensibilización, de adiestramiento de los oyentes, la danza, a su vez, muestra un repertorio de movimientos y, sobre todo, de actitudes corporales que, una vez liberada de las coreografías clásicas, se convierten en un acceso al cuerpo.

El relevo lo tomaría rápidamente el cine, consciente del hechizo del movimiento al son de la música, no solo desde el punto de vista de la primera persona, sino desde el punto de vista vicario. El cine musical, en una parte no desdeñable, es cine de danza que, si musicalmente no se puede considerar como contemporánea, desde el punto de vista estricto de la coreografía sí que incorporaba elementos de la vanguardia a contextos inevitablemente conservadores y a argumentos ramplones. En este caso, se trataba de una creación ligada a los nuevos medios de comunicación que, por desgracia, no acogieron con tanto entusiasmo las propuestas de la música contemporánea.

El segundo momento específico de camino al cuerpo en movimiento con las menores mediaciones posibles Ilega en la neovanguardia y la figura clave es la de Merce Cunningham (1919-2009)25, discípulo de la pionera Marta Graham, muy vinculado a la realización de las obras de John Cage y a los movimientos artísticos de los años cincuenta y sesenta en los Estados Unidos. En colaboración también con el pintor Robert Rauschenberg, exploró las posibilidades de una indeterminación casi completa del movimiento, llevando a sus últimas consecuencias la revisión del concepto de coreografía. La aleatoriedad de las propuestas sonoras de Cage, que dejaba en manos de los instrumentistas y ejecutantes una buena parte de las decisiones interpretativas, fue llevada por Cunningham al

25. Cfr. Harris, M. (1997), Merce Cunningham: fifty years. New York, Aperture. Huschka, S. (2000), Merce Cunningham und der Moderne Tanz. Körperkonzepte. Choreographie und Tanzästhetik. Würzburg, Könighausen und Neumann; Kostelanetz, R. (1992), Merce Cunningham dancing in Space and Time. Chicago, A Capella Books. 
movimiento de los bailarines. Además, sin duda, amplió el repertorio de movimientos y gestos.

Maurice Béjart, Alwin Nikolais, Paul Taylor, Pina Bausch, Angeline Preljocaj han explorado, entre otros, los diferentes registros pendientes, unas veces en diálogo con propuestas musicales clásicas actualizadas desde el punto de vista del movimientos y de la escenografía, en otros casos uniendo la propuesta coreográfica con nuevas creaciones sonoras. En uno y otro caso, la danza ha abierto la posibilidad de integrar elementos e influencias procedentes de otras prácticas artísticas, como la performance o la colaboración e integración con propuestas multimediales, como la vídeodanza.

Un capítulo que no ha sido objeto todavía de estudios autónomos, pero que está muy ligado a la nueva presencia del cuerpo en la música y en las creaciones contemporáneas es el del gesto ${ }^{26}$. En la música histórica ha estado vinculado con la práctica instrumental y con la dirección coral y orquestal. Pero desde los procesos que han dado al traste con las prácticas habituales, ha emergido como un tema nuevo. Aunque se ha estudiado tradicionalmente como un elemento más de las técnicas respectivas de cada una de esas prácticas interpretativas, ha sido en los últimos años cuando han cobrado un cierto protagonismo. La descomposición del gesto del pianista, o del flautista, o del propio director, ha pasado a ser también un elemento susceptible de formar parte de la composición. En algunas propuestas radicales de Mauicio Kagel o de Carlos Santos, el gesto es casi el único elemento que queda de la música. Otros compositores, como José Luis de Delás, lo utilizan casi en la frontera con la danza. Es, en cualquier caso, un elemento que viene de antiguo, si se piensa en las referencias de Forkel en su biografía de Bach, a principios del siglo XIX, a la posición de las manos de éste mientras tocaba el clave, o, en nuestros días, en la revolución que supuso el comportamiento 'corporal' de Glenn Gould cuando interpretaba. Un elemento fronterizo entre la música, la danza y la pura gestualidad que, sin embargo, cobra importancia en multitud de obras que buscan la concisión expresiva o el establecimiento de nuevos códigos sígnicos.

La consecuencia inevitable de todos los procesos presentados y comentados como el 'giro sonoro' ha sido la modificación de la escucha. El adiestramiento que durante siglos había centrado la atención al discurso musical apoyándose en los elementos melódicos y rítmicos, se tropezó, desde las primeras composiciones atonales, con la imposibilidad de orientación. Incluso en la actualidad cabe la pregunta por lo que se escucha: ¿Qué es lo que hay que escuchar? ¿A qué elementos es necesario atender? ¿Cómo conseguir establecer algún tipo de

26. Boulez, P. (2003), El gesto de la música. Barcelona, Gedisa; Finn, W.J. (1960), The Art of Choral Conductor. Princeton, New Jersey, Summy-Birchard Music; Kaplan, A. (1985), Choral Conducting. New York, London, Norton. 
orientación en el conjunto sonoro? Las primeras escuchas de cualquier música que resulta nueva al oyente conllevan problemas similares: el de la orientación, el de la definición de los elementos, el de la captación, en algún nivel, de las posibles estructuras. Sucede con el flamenco, con el jazz y, por supuesto, con las mal Ilamadas clásicas o cultas.

Algunos de los autores que participaron en ese tránsito desde la música hacia el sonido como un todo, componían e investigaban desde el interior de la música pero en diálogo con los nuevos medios tecnológicos o con las nuevas prácticas artísticas. Pierre Schaeffer y John Cage representan las dos tendencias que, en la mitad del siglo XX, tienden un puente desde la música a su ampliación. Y Murray R. Schafer universalizó la preocupación por el sonido convirtiéndola en un capítulo fundamental de la ecología, de la preocupación por la relación del ser humano con el medio natural y urbano en tanto que paisaje sonoro. Si bien es cierto que el sonido es el protagonista de cualquier práctica artística, histórica o actual, que quiera afectar al individuo a través del oído, también lo es que solo desde una escucha preparada para recibir esas propuestas se puede volver a pensar la estética.

Estos elementos -giro sonoro, danza, gesto, vocalidad- no han sido tan valorados como otros ni por la musicología ni por las tendencias posmodernas. Se sigue hablando de música cuando tal vez habría que dar el paso a unos estudios sonoros que estén a la altura del marco ampliado por la creación sonora. La conclusión de estas reflexiones es, entonces, no solo teórica, sino que plantea una verdadera tarea: una tarea de construcción de una nueva aproximación que asuma la complejidad de todo lo que rodea a la música pero que vaya más allá. ¿Algo más que música? Sí: la creación sonora.

\section{Bibliografía}

ADORNO, T. W. (1971). Teoría estética. Madrid, Taurus.

AUNER, J., LOCHHEAD, J. (eds.) (2002). Postmodern Music. Postmodern Thought. London-New York, Routledge.

DIEDERICHSEN, D. (2007). Argument son. De Britney Spears à Helmut Lachenmann: critique électro-acoustique de la société. Trad. Nicole Thiers. Dijon, Les presses du réel.

EAGLETON, F. (2005). Después de la teoría. Trad. Ricardo García Pérez. Barcelona, Debate.

—,(2006). La estética como ideología. Trad. Ramón del Castillo y Germán Cano. Madrid, Trotta.

FINKIELKRAUT, A. (1990). La derrota del pensamiento. Trad. Joaquín Jordá. Barcelona, Anagrama.

- (2006). Nosotros los modernos. Trad. Miguel Montes. Madrid, Encuentro.

FOSTER, H. (ed.) (1985). La posmodernidad. Barcelona, Kairos. 
GARCÍA LABORDA, J. M. (2004). La música moderna y contemporánea a través de los escritos de sus protagonistas (una antología de textos comentados). Sevilla, Doble J.

HABERMAS, J. (1988). "Modernidad versus postmodernidad". En Modernidad y postmodernidad, compilación de Josep Picó, pp. 87-102. Madrid, Alianza Editorial.

HUXLEY, A. (2003). Música en la noche. Trad. Miguel Martínez-Lage. Barcelona, Cairos.

KAIERO CLAVER, A. (2007). Creación musical e ideologías: la estética de la postmodernidad frente a la estética moderna. Tesis doctoral. Universitat Autònoma de Barcelona. Departament d'Art. Disponible en: http://www.tdx.cat/handle/ $10803 / 5197$.

KRAMER, J. D. (2002). "The Nature and Origins of Musical Postmodernism". En Postmodern Music. Postmodern Thought, Joseph Auner y Judy Lochhead (eds.). London-New York, Routledge, pp. 13-26.

RAMAUT-CHEVASSUS, B. (1998). Musique et postmodernité. París, P.U.F.

REYNOLDS, S. (2010). Después del rock. Psicodelia, postpunk, electrónica y otras revoluciones inconclusas. Trad. Gabriel Livov. Buenos Aires, Caja Negra, 2010.

-, (2012). Retromanía. La adicción del pop a su propio pasado. Buenos Aires, Caja Negra.

ROSS, A. (2009). El ruido eterno. Escuchar al siglo XX a través de su música. Trad. Luis Gago. Barcelona, Seix Barral.

—, (2012). Escucha esto. Trad. Luis Gago. Barcelona, Seix Barral. 